\title{
Enzymatic degradation of polyhydroxyalkanoate using lipase from Bacillus subtilis
}

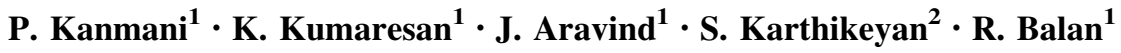

Received: 14 July 2015/Revised: 7 March 2016/Accepted: 12 April 2016/Published online: 3 May 2016

(C) Islamic Azad University (IAU) 2016

\begin{abstract}
Polyhydroxyalkanoates (PHAs) are an important class of biodegradable polymers synthesized by a few bacteria under nutrient-limiting conditions. In this study, the lipase-catalysed degradation of PHA synthesized by Enterobacter sp. was monitored. For this, the lipase-encoding gene from Bacillus subtilis DI2 was PCR-amplified, cloned into a $\mathrm{T}$ vector system and sequenced. It was expressed in Escherichia coli $\mathrm{DH} 5 \alpha$ cells, the recombinant enzyme was purified 24.25-fold, and its molecular weight was determined to be around $28 \mathrm{kDa}$. When PHA biodegradation studies were carried out with this enzyme, gel permeation chromatography showed 21.3 and $28.3 \%$ molecular weight decrease and weight loss, respectively. Further, scanning electron micrographs revealed alterations in polymer surface morphology. Changes in molecular vibrations were noticed in the FTIR spectra. When the chemical shifts in NMR spectra were studied, a steep reduction in area under the peak at $1.57 \mathrm{ppm}$ was observed. In the heating range of $30-930{ }^{\circ} \mathrm{C}$ employed during thermogravimetry analysis, the degraded sample showed a total of $45.82 \%$ weight loss, as against $18.89 \%$ for the native sample. The melting temperature $\left(T_{\mathrm{m}}\right)$ of the polymer was also brought down from 126.22 to $118.18^{\circ} \mathrm{C}$, as inferred from differential scanning calorimetry. Lipase-catalysed chain scission reactions could thus be used to generate low molecular weight functional biopolymers with wide-ranging pharmaceutical applications, such as in sustained drug release.
\end{abstract}

J. Aravind

dr.j.aravind@gmail.com

1 Department of Biotechnology, Kumaraguru College of Technology, Coimbatore 641049, India

2 School of Biosciences and Technology, VIT University, Vellore 632014, India
Keywords PHA biodegradation · FTIR $\cdot$ Melting temperature $\cdot$ Weight loss

\section{Introduction}

Polyhydroxyalkanoates (PHAs) are biopolymers that are accumulated by certain bacteria and archaea as internal storage granules under conditions of stress. Nitrogen or phosphorus limitation coupled with an excess of carbon in the growth medium triggers PHA accumulation. Ralstonia eutropha (Fiorese et al. 2009), Bacillus megaterium (Obruca 2010) and Cyanabacteria (Sharma and Mallick 2005) are some of the organisms whose PHA synthesis has been extensively characterized. PHAs are considered to be potential alternatives to the fossil fuel-based conventional polymers, since they can be produced using renewable raw materials. Moreover, their mechanical and thermal stabilities are often comparable to the conventional plastics such as polyethylene and polypropylene (Khanna and Srivastava 2005). Thermoplasticity, hydrophobicity, biocompatibility and biodegradability are properties that make these biopolymers attractive options for various medical, agricultural, food packaging and other applications (Philip et al. 2007). Poly-3-hydroxybutyrate (PHB), a linear homopolymer consisting of repeating 3-hydroxybutyric acid units, is the commonest form of PHA. Useful copolymers such as poly-3-hydroxybutyrate-co-4-hydroxybutyrate are also synthesized depending on the microorganisms used and the fermentation conditions (Rahayu et al. 2008).

The molecular weight of PHA produced by microorganisms is in the range of $200-3000 \mathrm{kDa}$ (Sudesh et al. 2000). High molecular weight PHAs are unsuitable for 
certain applications such as the design of special polymers for use in biodegradable nanoparticles (Chen et al. 2006). Acid, base and thermal hydrolysis used earlier to obtain low molecular weight polymers face drawbacks (Lauzier et al. 1994; Hauttecoeur et al. 1994; Nguyen et al. 2002). Hence, the biological route to degradation is more viable. These biopolymers are biodegradable under normal environmental conditions, and their biodegradation under aerobic conditions has been well studied. Bacteria such as Bacillus pumilis (Motiwalla et al. 2013), Pseudomonas sp. (Colak and Guner 2004) and fungi such as Aspergillus sp. (Sanchez et al. 2000) have been isolated, which are capable of degrading PHA types including PHB and polycaprolactone (PCL). These microorganisms produce intracellular and extracellular depolymerases that degrade the PHA into short oligomers and monomers which are subsequently utilized as carbon and energy sources by them.

Lipases (triacylglycerol acylhydrolases E.C. 3.1.1.3), which catalyse the hydrolysis of ester bonds, can play a prominent role in the degradation of PHA. They act at the oil-water interface of water-insoluble substrates. They possess a high degree of regio-, enantio- and chemoselectivities. They may also exhibit position specificity towards the ester bonds in positions 1 and 3 of the triacylglycerol and be unable to act on the ester bond at position 2, owing to steric hindrance. Lipases have been applied for the degradation of PHA in certain earlier studies (RodríguezContreras et al. 2012a, b). However, such studies have relied upon commercial lipases and not indigenous laboratory preparations, especially recombinant ones. The enzyme used in our study was derived from a lipolytic strain, Bacillus subtilis DI2. Its lipase-encoding gene was PCR-amplified, cloned into a $\mathrm{T}$ vector system and expressed in Escherichia coli DH5 $\alpha$ cells, and the recombinant enzyme was purified from it. Lipase-catalysed PHA degradation was then performed. The native and hydrolysed polymers were analysed and properties compared, to determine the extent of degradation.

\section{Materials and methods}

\section{Materials}

The bacterial strain $B$. subtilis DI2 that was previously isolated in our laboratory from dairy industry effluent, possessing established lipase activity and identified by $16 \mathrm{~S}$ rDNA sequencing (NCBI GenBank Accession No. KJ000043), was used in the study. pGEM-T vector was used as the cloning vector. E. coli DH5 $\alpha$ cultivated at $37{ }^{\circ} \mathrm{C}$ in Luria-Bertani (LB) broth containing (per L) tryptone $-10 \mathrm{~g}$, yeast extract $-5 \mathrm{~g}$ and $\mathrm{NaCl}-10 \mathrm{~g}$ was used as the expression host. The biopolymer sample used in the study was PHA synthesized earlier in our laboratory by a novel strain of Enterobacter sp. (Vinish et al. 2015). pNitrophenyl palmitate for lipase assay was purchased from Sigma-Aldrich, USA. All other chemicals were of AR grade and commercially available in India.

\section{Cloning and sequencing of the lipase-encoding gene}

All genetic manipulations were carried out as per the protocols of Sambrook and Russell (2001). Lipase gene-specific primers were designed based on the sequences available for Bacillus lipases in the database (Accession Nos. KF040967.1, CP004065.1, HE617159.1 and CP006952.1). The primers used were forward $5^{\prime}$ CCGCATATGAAACATATAAAAAG CA AAATCC $3^{\prime}$ and reverse $5^{\prime}$ CGGGATCCTTAATTTGTA TTTTGTCCGCCG3' ${ }^{\prime}$ Taq polymerase was used to perform PCR amplification with $B$. subtilis genomic DNA as the template. The conditions for PCR were as follows: one initial denaturation step at $94{ }^{\circ} \mathrm{C}$ for $2 \mathrm{~min} ; 30$ cycles of elongation at $72{ }^{\circ} \mathrm{C}$ for $30 \mathrm{~s} \mathrm{each}$; and annealing at $48{ }^{\circ} \mathrm{C}$ for $30 \mathrm{~s}$. The PCR product was electrophoretically resolved on $0.8 \%$ agarose gel, and the appropriate DNA fragment was cut carefully from the gel and purified by the silica method. This purified DNA fragment was ligated into a pGEM-T vector system using T4 DNA ligase, and competent $E$. coli DH5 $\alpha$ cells were transformed with the ligated product. The cells were plated on LB-AMP plates containing $100 \mathrm{mg} / \mathrm{L}$ of ampicillin (AMP), the inducer isopropyl thiogalactoside (IPTG) and the substrate $\beta$-D-galactoside (X-gal) to screen for transformants. Plasmids were isolated from the transformed colonies, and retardation checks were performed. The clones were also checked for insert release.

The clone containing the correct insert was identified, and its nucleotide sequence was determined using $\mathrm{ABI}$ PRISM 3100 genetic analyser (Applied Biosystem). The forward and reverse sequences were aligned using ClustalX 1.83 and deposited in the NCBI GenBank database. The nucleotide sequence was converted to the corresponding protein sequence, and similarity searches were performed in the NCBI Protein database. Phylogenetic tree was constructed (Kimura 1980) using the neighbour joining method. Needleman-Wunsch algorithm was used to create an optimal global alignment with the closest match in the database. Molecular weight and isoelectric point for the predicted protein were also calculated.

\section{Gene expression and purification of the recombinant lipase}

The transformed colonies were screened by checking for extracellular and intracellular lipase activities using tributyrin agar (TBA) plates. They were grown for $48 \mathrm{~h}$ in LB broth and the cells harvested by centrifuging at $8000 \mathrm{~g}$ for 
$10 \mathrm{~min}$. The supernatant was used as extracellular extract. The pellet was suspended in $100 \mathrm{mM}$ phosphate buffer $\mathrm{pH}$ 7.5 , sonicated using $4 \times 15 \mathrm{~s}$ pulses, the cell debris removed by centrifugation at $10,000 \mathrm{~g}$ for $10 \mathrm{~min}$, and the supernatant used as the intracellular enzyme extract. Fifty micro litre of the extracts was added to wells cut in TBA plates and observed for zones of clearance. The activity was further quantified using spectrophotometric assay with $p$-nitrophenyl palmitate ( $p$-NPP) as substrate (Winkler and Stuckmann 1979). The absorbance was measured at $410 \mathrm{~nm}$, against an enzyme-free blank. Molar extinction coefficient of $0.0146 \mu \mathrm{M}^{-1} \mathrm{~cm}^{-1}$ was used. One unit of lipase activity was defined as $\mu \mathrm{M}$ of $p$-nitrophenol released per minute under the assay conditions. All activity assays were performed in triplicate, and the values given represent the mean.

For lipase purification, LB broth was inoculated with $2 \%(\mathrm{v} / \mathrm{v})$ seed culture of the E. coli clone (overnight grown, cell density $43 \times 10^{6} \mathrm{CFU} / \mathrm{ml}$ ) and cultured for $48 \mathrm{~h}$ at $37^{\circ} \mathrm{C}$. The cells were harvested by centrifugation, and the clear supernatant was subjected to $\left(\mathrm{NH}_{4}\right)_{2} \mathrm{SO}_{4}$ precipitation ( $75 \%$ saturation). It was then purified using an ion exchange column ( $80 \mathrm{~mm}$ long, $15 \mathrm{~mm}$ inner diameter and $6 \mathrm{ml}$ packed bed volume) packed with phosphocellulose PC-11. This column was equilibrated using ten bed volumes of $\mathrm{pH} 7.4$ equilibration buffer containing $10 \mathrm{mM} \mathrm{KPO}_{4}, 1 \mathrm{mM}$ EDTA, $50 \mathrm{mM} \mathrm{KCl}$ and $7 \mathrm{mM}$ 2-mercaptoethanol. The sample was loaded, and after washing the column with five bed volumes of the same buffer, it was eluted using a gradient of low-to-high salt buffer $(0-1.0 \mathrm{M} \mathrm{KCl})$. The collected fractions were assayed for lipase activity. They were also subjected to SDS-PAGE on a $12 \%$ separating gel (Laemmli 1970) to check for purity and to estimate molecular weight. The protein bands were stained using coomassie brilliant blue $\mathrm{R}-250$. This purified recombinant lipase was designated as LipDI2.

\section{Biodegradation of PHA}

The methodology for PHA biodegradation trials was modified from Rodríguez-Contreras et al. (2012b). A suspension of PHA was prepared by dissolving in chloroform, emulsifying with the help of $10 \mathrm{mM}$ sodium deoxycholate and removing the chloroform by heating at $70{ }^{\circ} \mathrm{C}$ for $1 \mathrm{~h}$ (Horowitz and Sanders 1994). This suspension was used for the lipase-catalysed biodegradation, and water was the only solvent present in the reaction mixture. Five milli litre of the polymer suspension containing $100 \mathrm{mg}$ PHA was taken in a vial, to which $1 \mathrm{ml}$ of purified lipase and $4 \mathrm{ml}$ of pH 8 Tris- $\mathrm{HCl}$ buffer were added. The vials were incubated in a water bath shaker set at $40{ }^{\circ} \mathrm{C}$ and $60 \mathrm{rpm}$. Samples were withdrawn at regular time intervals of 24,48 and $72 \mathrm{~h}$. The reaction was stopped by denaturing the enzyme upon heating at $100{ }^{\circ} \mathrm{C}$ for $5 \mathrm{~min}$. The samples were then centrifuged at $5000 \mathrm{~g}$ for $10 \mathrm{~min}$, and the pellet was washed with distilled water, re-suspended and again centrifuged. The pellet was finally dissolved in chloroform and centrifuged, the solvent was removed using a rotary evaporator, and the pure polymer was dried and subjected to various analyses. A blank without the enzyme was also similarly processed. All experiments were carried out in triplicate.

\section{Gel permeation chromatography (GPC)}

The measurements were taken using a Shimadzu CBM20Alite model GPC instrument equipped with RID-10A refractive index detector. Chloroform was used as the eluent at a flow rate of $1.0 \mathrm{ml} / \mathrm{min}$ with a stabilization pressure of 40 bars and a sample concentration of $2.0 \mathrm{mg} /$ ml. CTO-20A column oven and GPC804 column were used. Polystyrene of varying molecular weights served as standards $\left(3.7 \times 10^{2}-6.7 \times 10^{6} \mathrm{Da}\right)$. The samples and standards were dissolved in tetrahydrofuran (THF) at a concentration of $2.0 \mathrm{mg} / \mathrm{ml}$ and filtered through a $0.2-\mu \mathrm{m}$ filter, and $100 \mu \mathrm{l}$ samples were injected. THF also functioned as the mobile phase, and the flow rate was maintained at $1.0 \mathrm{ml} / \mathrm{min}$. The data were used to determine molecular weight decrease and per cent weight loss of the samples.

\section{Scanning electron microscopy (SEM)}

The surface morphologies of the polymer samples were analysed using CON-Quanta 200 Mark II Environmental Scanning Electron Microscope.

\section{Fourier transform infrared (FTIR) spectroscopy}

Nicolet 6700 FTIR Spectrometer was used to record the spectra of the native and lipase-treated PHA samples. About $0.01 \mathrm{mg}$ of the sample was ground with $0.02 \mathrm{mg}$ of dried potassium bromide pellets and cast as an ultrathin film on the carrier. The spectra were obtained in the frequency range of $4000-400 \mathrm{~cm}^{-1}$, with a resolution of $4 \mathrm{~cm}^{-1}$ for 10 scans (Sandhya et al. 2013).

\section{Nuclear magnetic resonance (NMR) spectroscopy}

Bruker AV 500 NMR spectrometer was used for obtaining the ${ }^{1} \mathrm{H}$ NMR spectra of the native and enzyme-degraded polymer samples. The solvent system employed was deuterated chloroform, and tetramethylsilane was used as reference. The spectra were recorded at $300.1 \mathrm{MHz}$ with 32 data points, using 64 scans and a relaxation delay of $2 \mathrm{~s}$. 


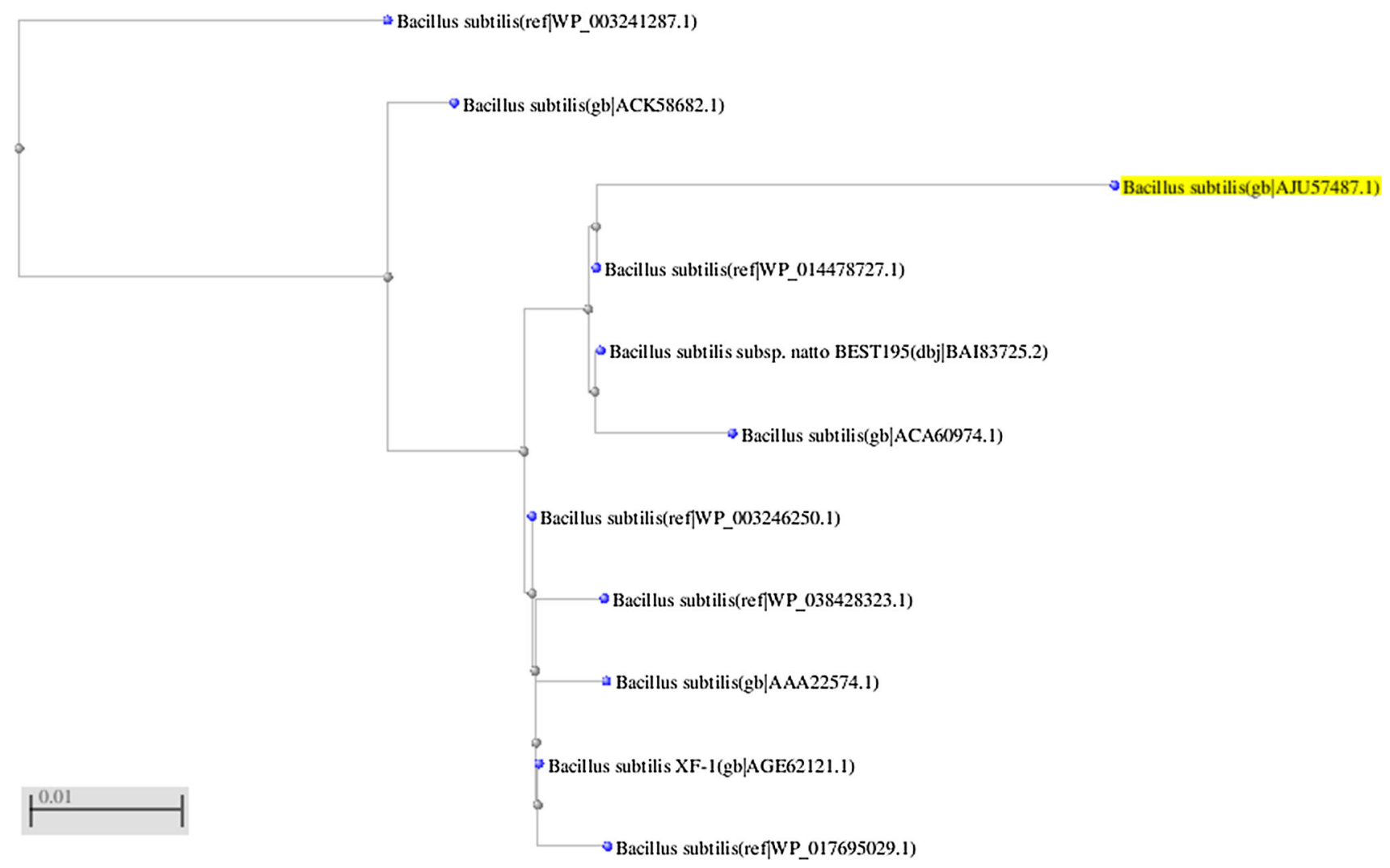

Fig. 1 Phylogenetic tree for Bacillus subtilis DI2 lipase. Lipase genespecific primers forward 5'CCGCATATGAAACATATAAAAAGCA AAATCC 3 and reverse 5'CGGGATCCTTAATTTGTATTTTGTCC GCCG $^{\prime} 3$ were used for DNA amplification. pGEM-T vector was used for cloning. Nucleotide sequencing was performed using ABI PRISM
3100 genetic analyser. Forward and reverse sequences were aligned using ClustalX 1.83 and converted to the corresponding peptide sequence, and BLASTp was performed. Neighbour joining method was used for construction of the phylogenetic tree
Fig. 2 Global sequence alignment of LipDI2 with the closest matching database sequence. The closest matching database sequence (WP_031600121.1) was used for obtaining the alignment. The conserved lipase motifs (A-X$\mathrm{S}-\mathrm{X}-\mathrm{G})$ and the regions of mismatch between the two sequences have been highlighted

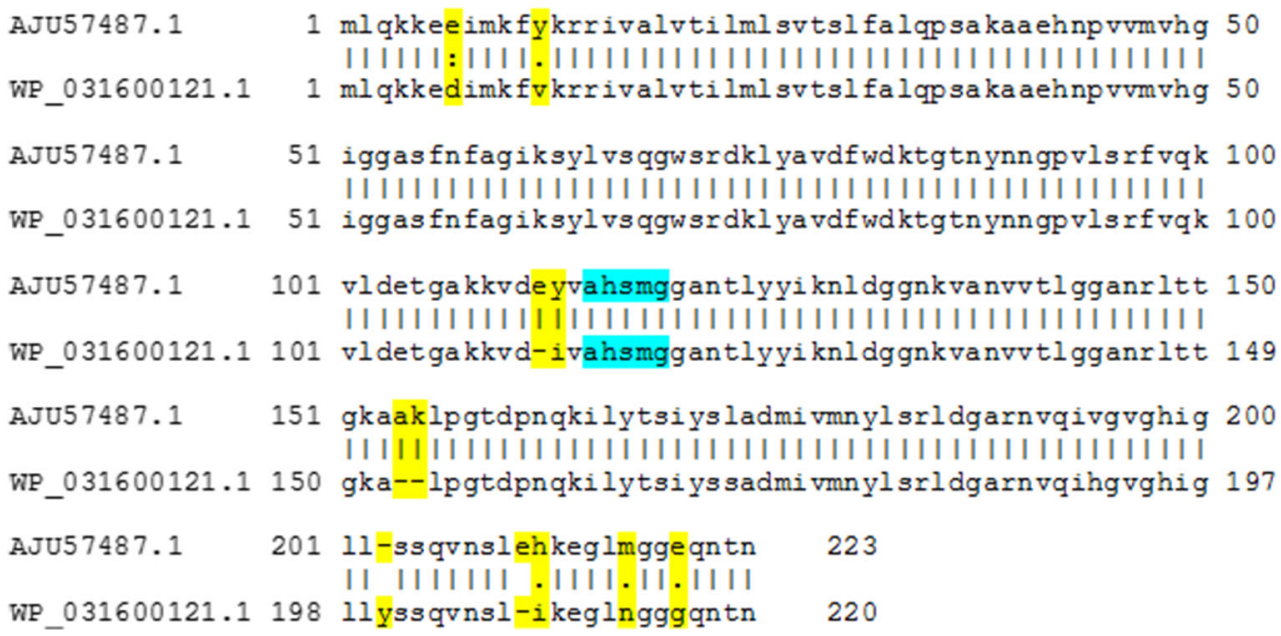

\section{Thermogravimetry analysis (TGA)}

TGA7 (PerkinElmer), Q500 Hi-Res TGA from TA instruments, was used to obtain measurements of weight change in the samples. The samples were heated from 30 to $930{ }^{\circ} \mathrm{C}$ at a heating rate of $10^{\circ} \mathrm{C} / \mathrm{min}$ under a nitrogen gas flow rate of $20 \mathrm{ml} / \mathrm{min}$.

\section{Differential scanning calorimetry (DSC)}

DSC7 (PerkinElmer), Q200 MDSC from TA instruments, was used, and the nitrogen gas flow rate was $50 \mathrm{ml} / \mathrm{min}$. The instrument was calibrated using pure indium. A sample of $5 \mathrm{mg}$ was taken in sealed aluminium planchets. The starting temperature for the scan 


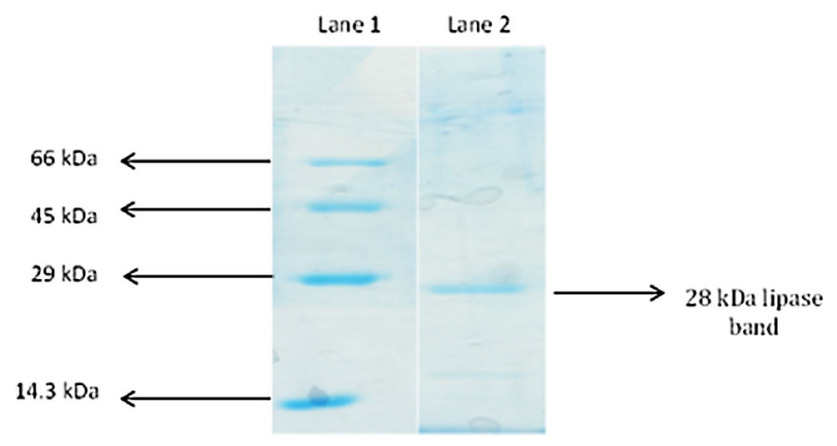

Fig. 3 SDS-PAGE of the purified lipase sample. Lane 1 Molecular weight markers, Lane 2 Purified lipase sample, showing a band at around $28 \mathrm{kDa}$

was $25^{\circ} \mathrm{C}$ and was hiked at the rate of $10{ }^{\circ} \mathrm{C} / \mathrm{min}$ to a final temperature of $205^{\circ} \mathrm{C}$. The measurement was used to understand details of changes in the polymer, such as the melting temperature $\left(T_{\mathrm{m}}\right)$ and the melting enthalpy $\left(\Delta H_{\mathrm{m}}\right)$. The peak of the thermogram was taken to be the $T_{\mathrm{m}}$.

\section{Results and discussion}

\section{Cloning and sequencing of the lipase-encoding gene}

Degenerate oligonucleotide primers resulted in the amplification of 669-bp-long fragment from the genomic DNA of B. subtilis DI2 strain. Its nucleotide sequence was submitted to NCBI GenBank database with the Accession No. KP137412. It coded for a 223-amino acid-long protein sequence (NCBI Protein database Accession No. AJU57487). The phylogenetic tree depicting sequence relationships between LipDI2 and other lipase sequences in the protein database is given in Fig. 1. Global sequence alignment of LipDI2 with the closest matching database sequence (WP_031600121) is depicted in Fig. 2. The alignment showed $94.6 \%$ similarity, $94.2 \%$ identity and $2.2 \%$ gaps, resulting in a score of 1022.5. The molecular weight of the predicted protein was calculated to be $24.28 \mathrm{kDa}$ and the isoelectric point to be 9.9272. It showed a 0.924 improbability of being expressed in inclusion bodies.

\section{Gene expression and purification of the recombinant lipase}

Gene expression was confirmed by checking for lipase activity in the intracellular and extracellular fractions of the clone culture. When the TBA plate assay was performed, good clearance zones were observed around wells containing the culture supernatant, thereby establishing lipase production and secretion into the growth medium. This was further quantified using $p$-NPP assay, which yielded an activity of $29.14 \mathrm{U} / \mathrm{ml}$. Control assays involving native $E$. coli DH5 $\alpha$ cells without the cloned gene did not exhibit positive result.

Enzyme purification was carried out with $1 \mathrm{~L}$ of the E. coli clone culture, whose supernatant was subjected to $\left(\mathrm{NH}_{4}\right)_{2} \mathrm{SO}_{4}$ precipitation. When applied onto PC-11 column, fractions 6-8 showing the highest absorbance (data not shown) were pooled and dialysed against equilibration buffer containing $50 \%$ glycerol for $16 \mathrm{~h}$ in cold conditions. It was then loaded on SDS-PAGE, and the lipase band was seen at around $28 \mathrm{kDa}$, as represented in Fig. 3. In another study, a purified recombinant $B$. subtilis lipase had demonstrated a band at $24 \mathrm{kDa}$. Purification chart is summarized in Table 1. The lipase was purified 24.25-fold with a yield of $3.87 \%$. Earlier, the purity of a recombinant B. subtilis lipase had been increased approximately 19.7fold over the crude extract, after ion exchange and gel filtration chromatographic separations (Ma et al. 2006). The purified lipase preparation thus obtained was used for the PHA biodegradation study.

Table 2 Effect of enzymatic degradation on the weight of PHA sample

\begin{tabular}{lll}
\hline Time (h) & Molecular weight decrease (\%) & Weight loss (\%) \\
\hline 0 & - & - \\
24 & $8.20 \pm 0.20$ & $10.4 \pm 0.24$ \\
48 & $15.3 \pm 0.18$ & $19.3 \pm 0.37$ \\
72 & $21.3 \pm 0.51$ & $28.3 \pm 0.10$ \\
\hline
\end{tabular}

Table 1 Purification chart for LipDI2

\begin{tabular}{|c|c|c|c|c|c|c|c|}
\hline S. no & Samples & $\begin{array}{l}\text { Total volume } \\
\text { (ml) }\end{array}$ & $\begin{array}{l}\text { Total activity } \\
\text { (U) }\end{array}$ & $\begin{array}{l}\text { Protein recovery } \\
(\mathrm{mg})\end{array}$ & $\begin{array}{l}\text { Specific activity } \\
(\mathrm{U} / \mathrm{mg})\end{array}$ & $\begin{array}{l}\text { Fold } \\
\text { purification }\end{array}$ & $\begin{array}{l}\text { Yield } \\
(\%)\end{array}$ \\
\hline 1. & Crude extract & 1000 & 1654 & 252 & 6.6 & 1.0 & 100 \\
\hline 2. & $\left(\mathrm{NH}_{4}\right)_{2} \mathrm{SO}_{4} 75 \%$ cut & 15 & 892 & 79 & 11.28 & 1.71 & 53.92 \\
\hline 3. & PC-11 column & 2 & 34.48 & 0.127 & 273.65 & 24.25 & 3.87 \\
\hline
\end{tabular}




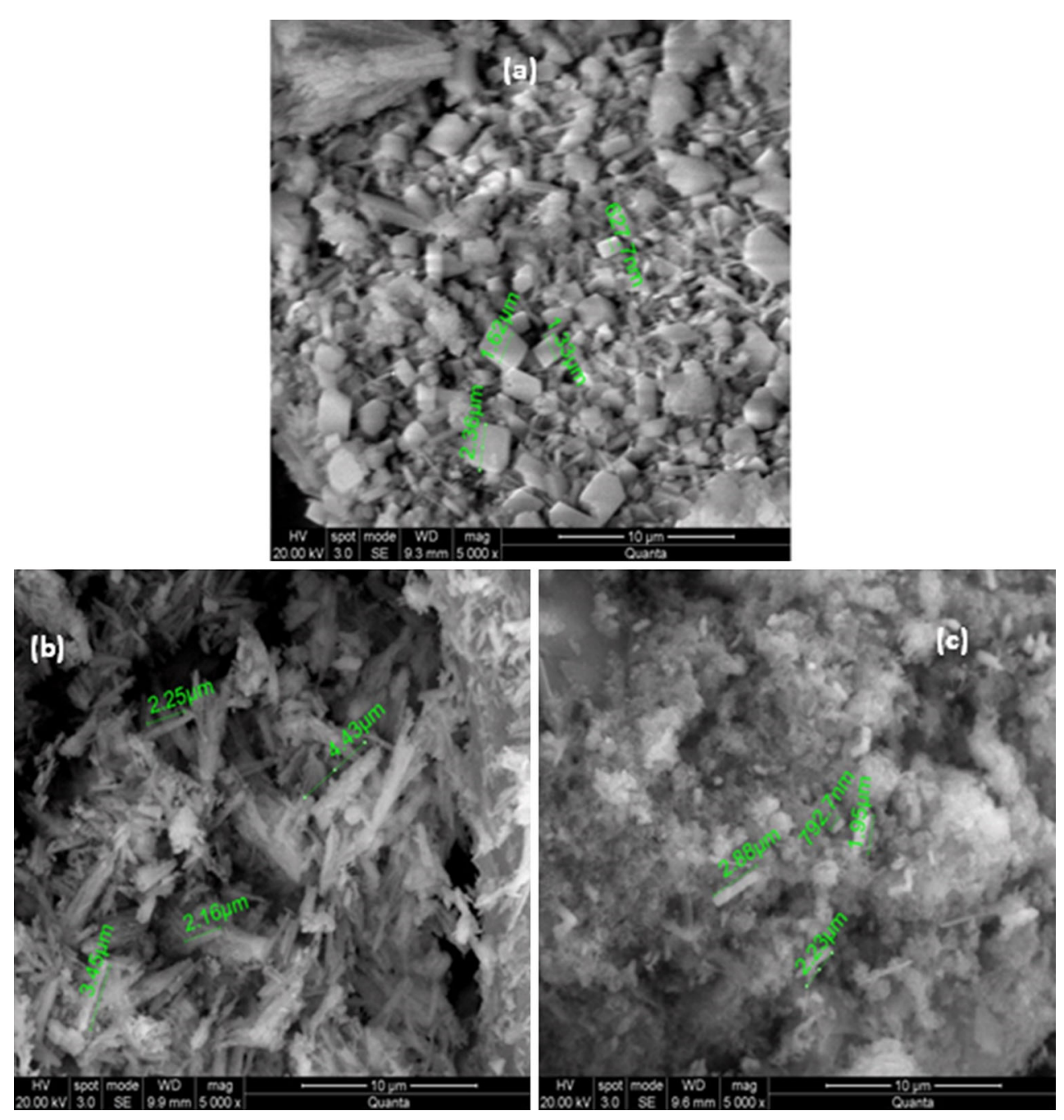

Fig. 4 SEM images of native (a) and enzymatically degraded (b, c) PHA samples

\section{Biodegradation of PHA}

\section{Gel permeation chromatography}

Changes in molecular weight were determined by GPC analysis of samples withdrawn from the reaction mixture at different time intervals (Table 2). A $10.4 \%$ decrease in molecular weight was witnessed in the sample after $24 \mathrm{~h}$ of contact with the enzyme, which went up to $21.3 \%$ within $72 \mathrm{~h}$. This is suggestive of a lesser degree of control in polymer size distribution (Gumel et al. 2012) as a result of random hydrolytic action.

In addition to molecular weight changes, per cent weight loss of the PHA sample was also checked. Upon incubation with lipase, the sample faced 9.2, 17.2 and $23.3 \%$ weight losses after 24,48 and $72 \mathrm{~h}$ of exposure to lipase, respectively. In a comparable study in which three different strains of Pseudomonas were tested for their poly(3-hydroxybutyrate)-degrading efficiency, $P$. aeruginosa had caused a maximum of 17.1 and $29.2 \%$ molecular weight decrease and weight loss, respectively (Colak and Guner 2004).

\section{Scanning electron microscopy}

Further evidence for the biodegradation of PHA samples was provided by the SEM images. Images taken before and after biodegradation are comparatively presented in Fig. 4 . The native, undegraded sample is shown in Fig. 4a, while $4 \mathrm{~b}$ and $\mathrm{c}$ depict the enzyme-degraded PHA samples, subjected to 48 and $72 \mathrm{~h}$ of contact with the lipase, respectively. A visible decrease in individual particle sizes of the samples could be discerned from the micrographs, which corroborates the data obtained in GPC study. 


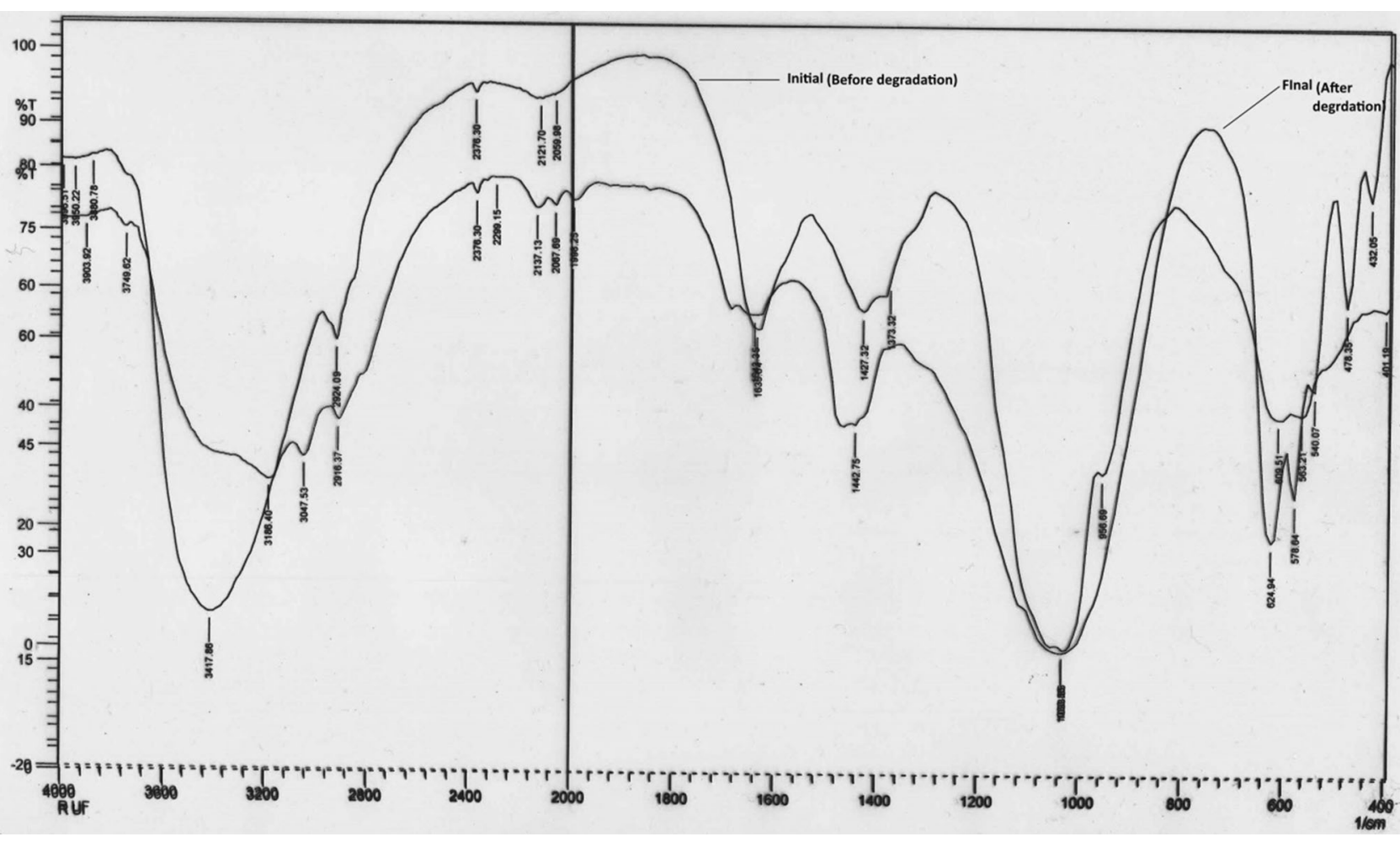

Fig. 5 Initial (a) and final (b) FTIR spectra of the PHA sample

\section{FTIR spectroscopy}

The FTIR spectra recorded before and after the enzymatic degradation of the polymer sample are presented in Fig. 5a and b, respectively. In Fig. 5a, the strong and broad peak at $3417 \mathrm{~cm}^{-1}$ indicates the $\mathrm{O}-\mathrm{H}$ stretch and $\mathrm{H}$-bonded vibrations. The presence of the $\mathrm{O}-\mathrm{H}$ group also confirms the linearity of the polymer chain. The sharp peak at $2924 \mathrm{~cm}^{-1}$ corresponds to $\mathrm{C}-\mathrm{H}$ stretch. The weak peak at $2121 \mathrm{~cm}^{-1}$ indicates $\mathrm{C} \equiv \mathrm{C}$ stretching vibration. The presence of $\mathrm{C}=\mathrm{C}$ stretch (conjugated) is indicated by the peak at $1635 \mathrm{~cm}^{-1}$. $\mathrm{C}-\mathrm{C}$ stretch (in ring) and $\mathrm{C}-\mathrm{O}$ stretch are attributed to the peaks at 1427 and $1033 \mathrm{~cm}^{-1}$, respectively.

In Fig. 5b, certain differences in molecular vibrations are witnessed due to the polymer degradation. $\mathrm{O}-\mathrm{H}$ stretching vibration is confirmed by a medium peak obtained at $3186 \mathrm{~cm}^{-1}$ and $\mathrm{C}-\mathrm{H}$ stretching vibration by medium peaks recorded at 3047 and $2916 \mathrm{~cm}^{-1}$. The $\mathrm{C} \equiv \mathrm{C}$ stretching vibration is also observed, but the peak is shifted to $2137 \mathrm{~cm}^{-1}$. The peak at $1643 \mathrm{~cm}^{-1}$ is due to the $\mathrm{C}=\mathrm{C}$ stretch (isolated), and the one at $1442 \mathrm{~cm}^{-1}$ is due to $\mathrm{C}-\mathrm{C}$ stretching vibration. $\mathrm{C}-\mathrm{O}$ stretch is indicated by a strong peak at $1033 \mathrm{~cm}^{-1}$. The peak at $624 \mathrm{~cm}^{-1}$ is due to acetylenic $\mathrm{C}-\mathrm{H}$ bend. The peaks at $578 \mathrm{~cm}^{-1}$ and $540 \mathrm{~cm}^{-1}$ are due to $\mathrm{C}-\mathrm{Br}$ stretch, and the ones at 478 and $432 \mathrm{~cm}^{-1}$ are due to C-I stretch.

These spectral changes provide information on the types of bonds that were hydrolysed, and the preference shown by lipase in this regard is in agreement with the observations made by other researchers (Kuntanoo et al. 2013).

\section{NMR spectroscopy}

The NMR spectra of PHA samples obtained before and after biodegradation are represented in Fig. 6. They help in judging the changes in molecular structure of the polymer that occur as a result of enzymatic hydrolysis. The number of peaks in the spectra indicates the number of nonequivalent protons in the molecule. The relative intensities of the signals indicate the numbers of protons that are responsible for individual signals. The area under each peak is measured in the form of an integral line. The height of the steps of this line is proportional to the area under the peak and therefore indicates the number of protons. The locations of the peaks (chemical shift, ppm) indicate the types of protons in the molecule. The number of sub-peaks in a cluster is one more than the number of hydrogen atoms attached to the next door carbon(s).

Two peaks were observed in the recorded spectra, signalling the presence of two non-equivalent protons. The chemical shifts in the region of $1.2-1.3 \mathrm{ppm}$ indicate the presence of secondary alkyl type of protons $\left(\mathrm{R}_{2}-\mathrm{CH}_{2}\right)$, and those in the region of 1.4-1.7 ppm indicate the presence of tertiary alkyl type of protons $\left(\mathrm{R}_{3}-\mathrm{CH}\right)$. Shifts in these regions were present in both the spectra, while their intensities varied. 
(a)

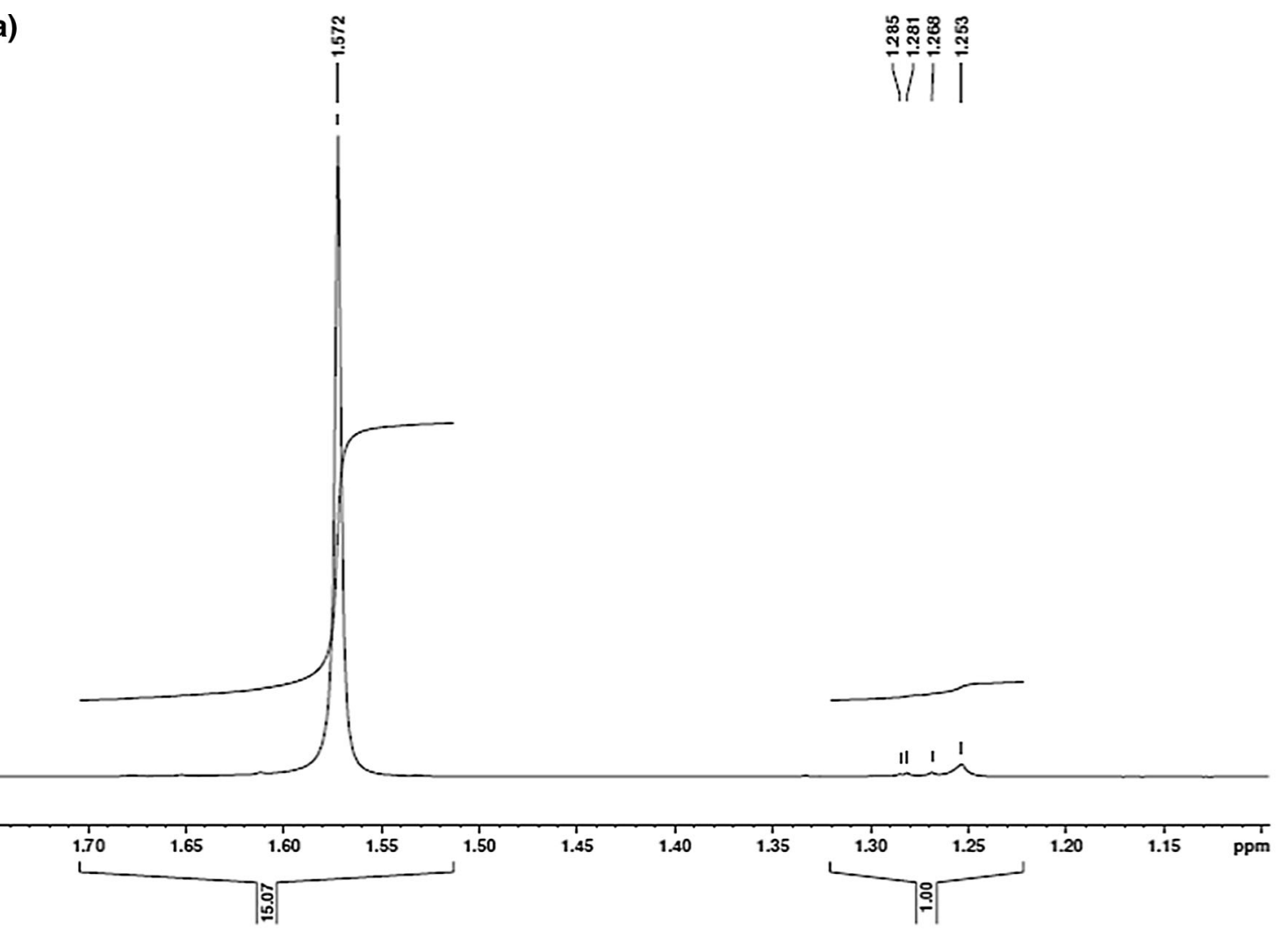

(b)
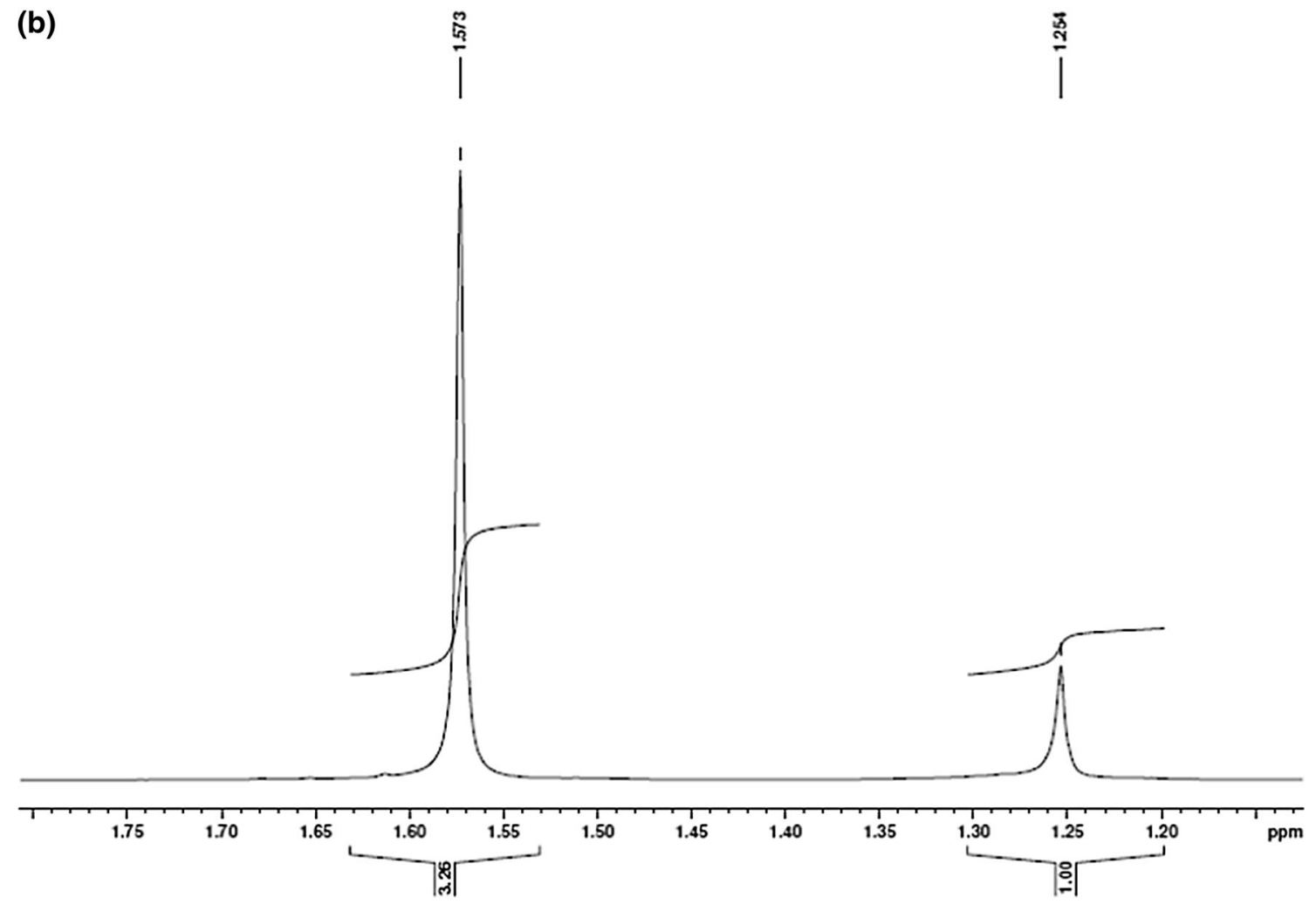

Fig. 6 Initial (a) and final (b) NMR spectra of the PHA sample 
(a)

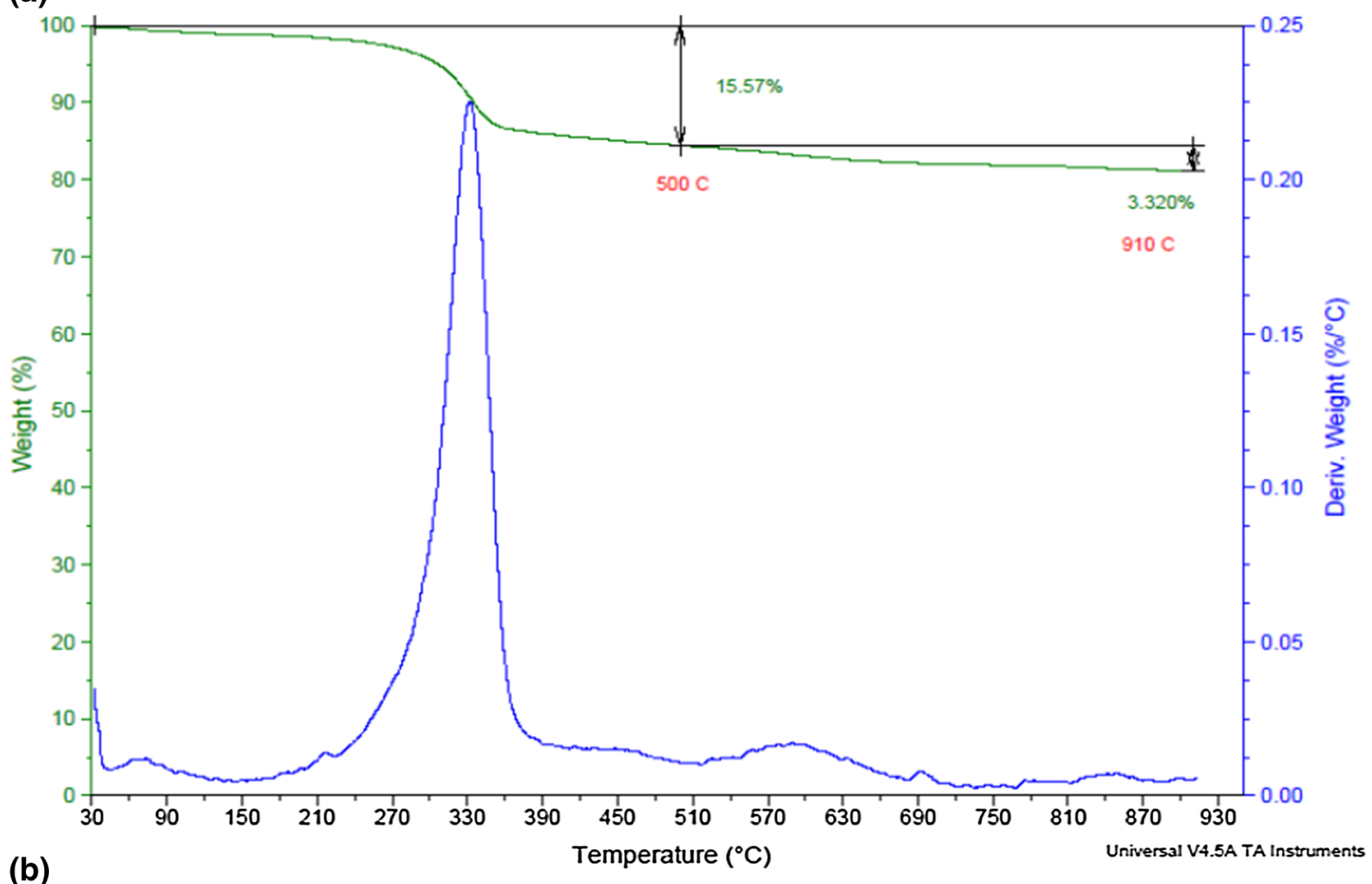

(b)

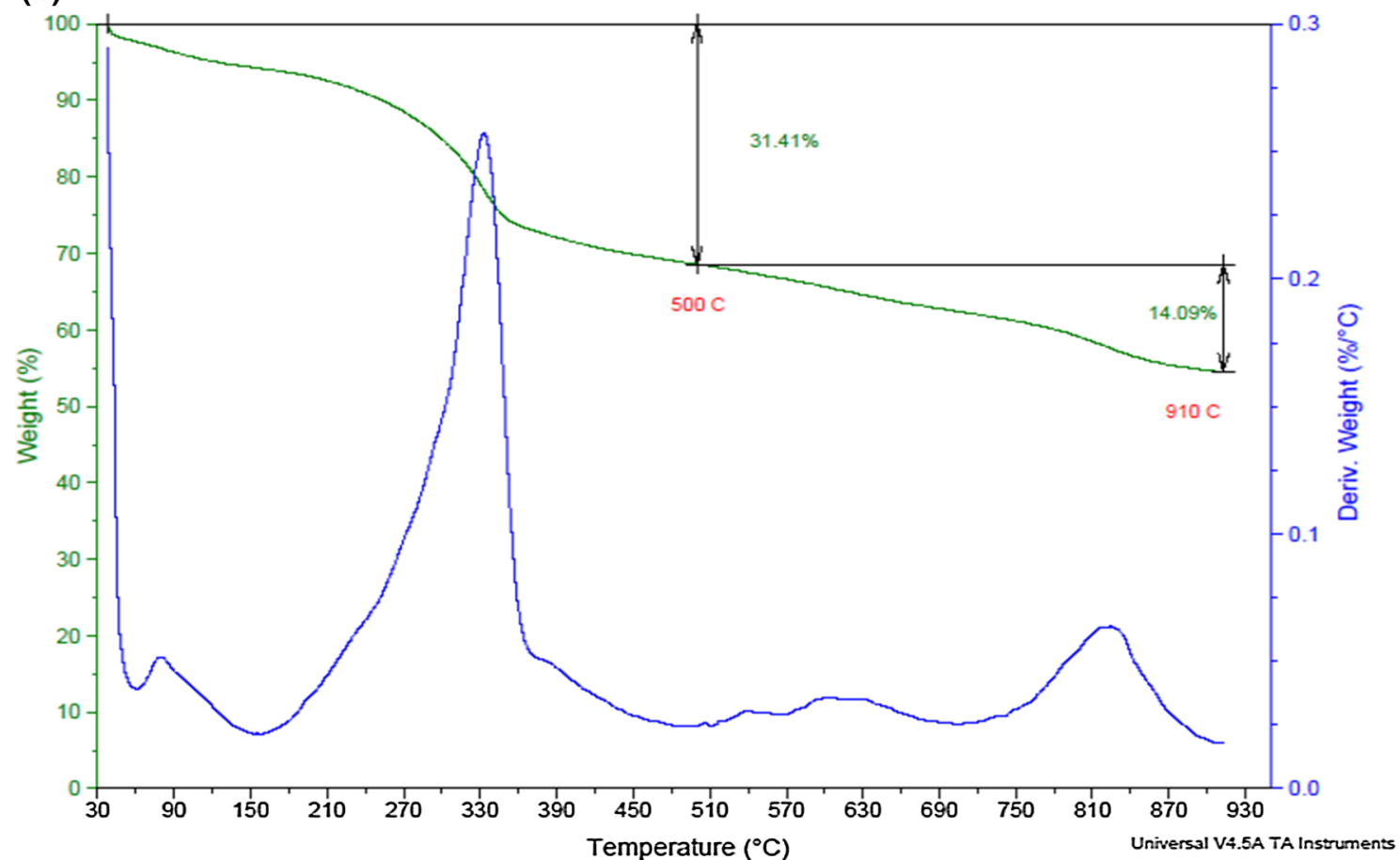

Fig. 7 Thermal decomposition profiles of native (a) and enzymatically degraded (b) PHA samples

Chemical shift at $1.29 \mathrm{ppm}$ has been reported as a main group of signal for PHB in another study, involving the enzymatic degradation of poly(3-hydroxybutyrate) by a commercial lipase (Rodríguez-Contreras et al. 2012a). In Fig. 6a, splitting of peaks occurred under high resolution, and a quartet (three hydrogen atoms attached to the carbon atom(s) next door) was observed at $1.2 \mathrm{ppm}$, while only singlets were observed in $6 \mathrm{~b}$. A marked decrease in area under the peak at $1.57 \mathrm{ppm}$ (15.07-3.26) was witnessed in the sample after the enzymatic degradation (Fig. 6b). 

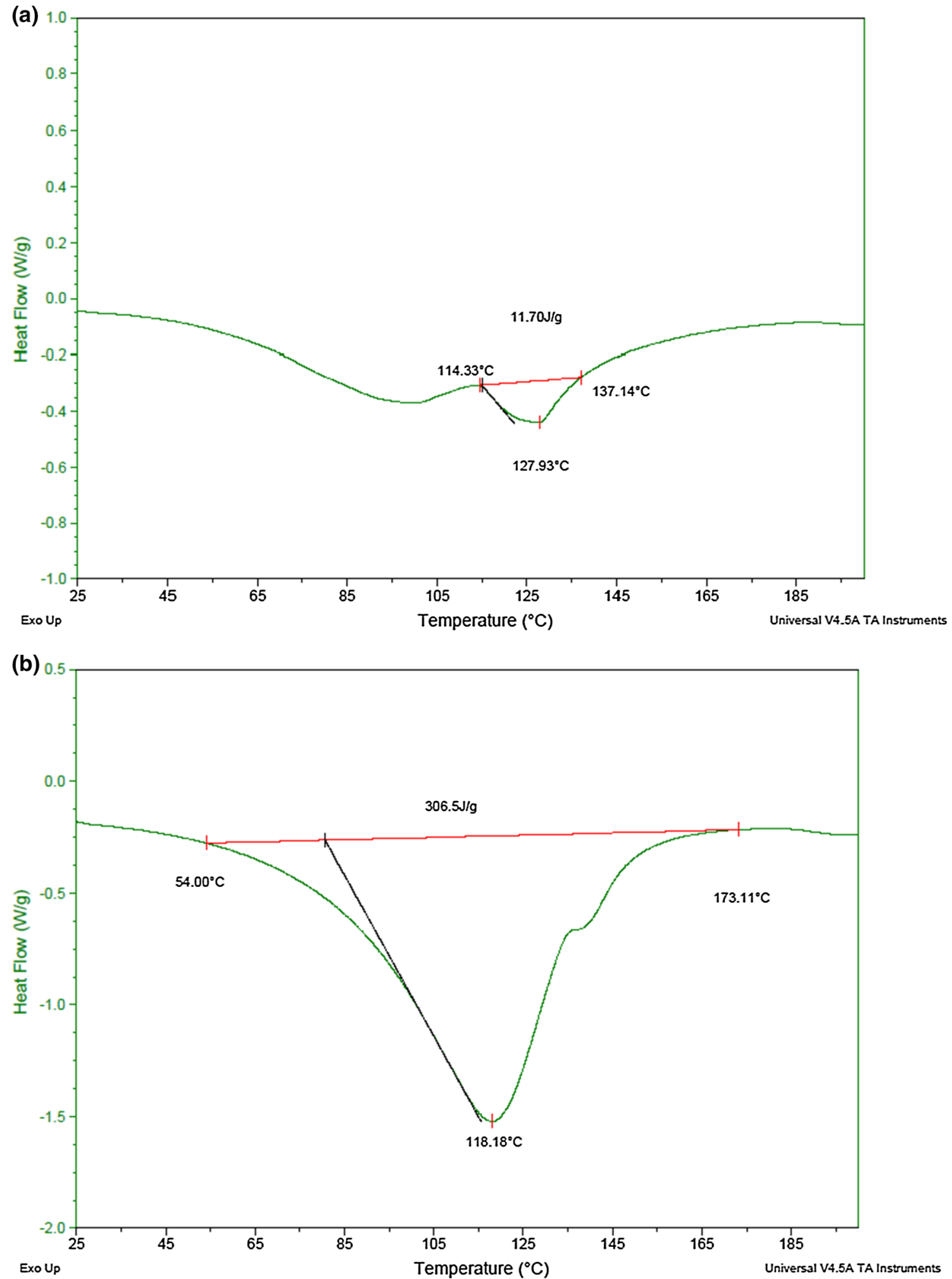

Fig. 8 Differential thermograms of native (a) and enzymatically degraded (b) PHA samples 


\section{Thermogravimetry}

Per cent weight loss of the PHA sample as a function of temperature was monitored by TGA analysis. The native PHA sample showed $15.57 \%$ weight loss upon heating from 30 to $500{ }^{\circ} \mathrm{C}$ and a further $3.32 \%$ weight loss when heated up to $910{ }^{\circ} \mathrm{C}$, thus facing a total of $18.89 \%$ weight loss in the entire heating range (Fig. 7a). The same sample, after $72 \mathrm{~h}$ of enzymatic degradation, suffered 31.41 and $14.41 \%$ weight losses in the above-mentioned temperature ranges, amounting to a total of $45.82 \%$ (Fig. 7b). These data prove that the enzyme-degraded sample undergoes more pronounced thermal decomposition than the native sample, which appears to have better thermal stability.

\section{Differential scanning calorimetry}

DSC results showed that $T_{\mathrm{m}}$ of the native sample was $126.22{ }^{\circ} \mathrm{C}$ and $\Delta H_{\mathrm{m}}$ was $2.16 \mathrm{~J} / \mathrm{g}$ (Fig. 8a). Higher $T_{\mathrm{m}}$ values of $171.33{ }^{\circ} \mathrm{C}$ (Bhuwal et al. 2013) and $176.29{ }^{\circ} \mathrm{C}$ (Tanamool et al. 2011) have been reported in the literature for PHA. Significantly lower $T_{\mathrm{m}}$ has also been reported. For instance, polyhydroxyhexanoate synthesized by $\mathrm{Can}$ dida antarctica lipase $\mathrm{B}$ with ultrasound assistance had displayed $T_{\mathrm{m}}$ of $58.46{ }^{\circ} \mathrm{C}$ (Gumel et al. 2012). $T_{\mathrm{m}}$ of the enzyme-degraded sample was lowered to $118.18{ }^{\circ} \mathrm{C}$, while $\Delta H_{\mathrm{m}}$ was increased to $306.5 \mathrm{~J} / \mathrm{g}$ (Fig. 8b). Such a fall in $T_{\mathrm{m}}$ further confirms the molecular weight reduction occurring during lipase-catalysed enzymatic hydrolysis of the polymer sample. In another study, the $T_{\mathrm{m}}$ of PHB has been reported to decrease from 173 to $160{ }^{\circ} \mathrm{C}$ after $72 \mathrm{~h}$ of contact with commercial lipase (Rodríguez-Contreras et al. 2012a).

\section{Conclusion}

Although PHA synthesis as well as biodegradation has been previously studied, the successful application of indigenously sourced lipase as well as biopolymer samples for this purpose sets it apart from other studies. Molecular weight decrease in the enzyme-degraded sample has been proven through GPC analysis. SEM results have indicated changes in particle size and surface morphology. NMR and FTIR data have shed light on lipase-induced structural and vibrational changes at the molecular level. Thermal decomposition profiles and differential thermograms have further aided in comparing the properties of native and enzyme-degraded samples, and a fall in $T_{\mathrm{m}}$ has been witnessed. These findings are suggestive of the recombinant $B$. subtilis lipase serving as a potential biocatalyst for effecting PHA biodegradation.
Acknowledgments The authors would like to thank the BU-DRDO Centre for Life Sciences, Coimbatore, for the SEM analysis; PSG College of Technology, Coimbatore, for the FTIR analysis; Department of Chemistry, IITM, Chennai, for TGA and DSC analyses; and SAIF-IITM, Chennai, for the NMR analyses.

\section{References}

Bhuwal AK, Singh G, Aggarwal NK, Goyal V, Yadav A (2013) Isolation and screening of polyhydroxyalkanoates producing bacteria from pulp, paper, and cardboard industry wastes. Int $\mathbf{J}$ Biomater 2013, 1-10, Article ID 75282

Chen C, Yu CH, Cheng YC, Yu PHF, Cheung MK (2006) Preparation and characterization of biodegradable nanoparticles based on amphiphilic poly(3-hydroxybutyrate)epoly(ethylene glycol)epoly(3-hydroxybutyrate) triblock copolymer. Eur Polym J 42:2211-2220

Colak A, Guner S (2004) Polyhydroxyalkanoate degrading hydrolaselike activities by Pseudomonas sp. isolated from soil. Int Biodeterior Biodegr 53:103-109

Fiorese M, Freita F, Pais J, Ramos AM, Aragao C, Reis M (2009) Recovery of polyhydroxybutyrate (PHB) from Cupriavidus necator biomass by solvent extraction with 1,2-propylene carbonate. Eng Life Sci 9:454-461

Gumel AM, Annuar MSM, Chisti Y, Heidelberg T (2012) Ultrasound assisted lipase catalyzed synthesis of poly-6-hydroxyhexanoate. Ultrason Sonochem 19:659-667

Hauttecoeur B, Jolivet M, Gavard R (1994) Depolymerization, by a controlled chemical process, of beta hydroxybutyric lipid (or PHB) of Bacillus megaterium. C R Acad Sci Hebd Seances Acad Sci D 274(19):2729-2732

Horowitz DM, Sanders JKM (1994) Amorphous, biomimetic granules of polyhydroxybutyrate: preparation, characterization, and biological implications. J Am Chem Soc 116:2695-2702

Khanna S, Srivastava AK (2005) Recent advances in microbial polyhydroxyalkanoates. Process Biochem 40:607-619

Kimura M (1980) A simple method for estimating evolutionary rates of base substitutions through comparative studies of nucleotide sequences. J Mol Evol 16(2):111-120

Kuntanoo K, Promkotra S, Kaewkannetra P (2013) Biodegradation of polyhydroxybutyrate-co-hydroxyvalerate (PHBV) blended with natural rubber in soil environment. Int Sci Index 7(12): waset.org/Publication/16662 (2013)

Laemmli UK (1970) Cleavage of structural proteins during the assembly of the head of bacteriophage T4. Nature 227:680-685

Lauzier C, Revol JF, Debzi EM, Marchessault RH (1994) Hydrolytic degradation of isolated poly(b-hydroxybutyrate) granules. Polymer 35:4156-4162

Ma J, Zhang Z, Wang B, Kong X, Wang Y, Cao S, Feng Y (2006) Overexpression and characterization of a lipase from Bacillus subtilis. Protein Expres Purif 45:22-29

Motiwalla M, Punyarthi P, Mehta M, D'Souza J, Kelkar-Mane V (2013) Studies on degradation efficiency of polycaprolactone by a naturally occurring bacterium. J Environ Biol 34:43-49

Nguyen S, Yu G-E, Marchessault RH (2002) Thermal degradation of poly(3-hydroxyalkanoates): preparation of well-defined oligomers. Biomacromol 3(1):219-224

Obruca S (2010) Controlled production and degradation of selected biomaterials. Dissertation, Brno University, Czech Republic

Philip S, Keshavarz T, Roy I (2007) Polyhydroxyalkanoates: biodegradable polymers with a range of applications. J Chem Technol Biotechnol 82(3):233-247

Rahayu A, Zaleha Z, Yahya ARM, Majid MIA, Amirul AA (2008) Production of copolymer poly(3-hydroxybutyrate-co-4- 
hydroxybutyrate) through a one-step cultivation process. World J Microbiol Biotechnol 24:2403-2409

Rodríguez-Contreras A, Calafell-Monfort M, Marqués-Calvo MS (2012a) Enzymatic degradation of poly(3-hydroxybutyrate) by a commercial lipase. Polym Degrad Stabil 97:2473-2476

Rodríguez-Contreras A, Calafell-Monfort M, Marqués-Calvo MS (2012b) Enzymatic degradation of poly(3-hydroxybutyrate-co-4hydroxybutyrate) by commercial lipases. Polym Degrad Stabil 97:597-604

Sambrook J, Russell DW (2001) Molecular cloning: a laboratory manual, 3rd edn. Cold Springs Harbor Laboratory, New York

Sanchez J, Tsuchii A, Tokiwa Y (2000) Degradation of polycaprolactone at $50^{\circ} \mathrm{C}$ by a thermotolerant Aspergillus sp. Biotechnol Lett 22:849-853

Sandhya M, Aravind J, Kanmani P (2013) Production of polyhydroxyalkanoates from Ralstonia eutropha using paddy straw as cheap substrate. Int J Environ Sci Technol 10(1):47-54
Sharma L, Mallick N (2005) Accumulation of poly-hydroxybutyrate in Nostoc musocrum: regulation by $\mathrm{pH}$, light-dark cycles, $\mathrm{N}$ and $\mathrm{P}$ status and carbon sources. Bioresour Technol 96:1304-1310

Sudesh K, Abe H, Doi Y (2000) Synthesis, structure and properties of polyhydroxyalkanoates: biological polyesters. Prog Polym Sci 25:1503-1555

Tanamool V, Imai T, Danvirutai P, Kaewkannetra P (2011) Biosynthesis of polyhydroxyalkanoate (PHA) by Hydrogenophaga sp. isolated from soil environment during batch fermentation. J Life Sci 5(12):1003-1012

Vinish V, Sangeetha SH, Aravind J, Kanmani P, Sathishkumar T (2015) Optimizing the nutrient feeding strategy for PHA production by a novel strain of Enterobacter sp. Int J Environ Sci Technol. doi:10.1007/s13762-015-0784-3

Winkler UK, Stuckmann M (1979) Glycogen, hyaluronate and some other polysaccharides greatly enhance the formation of exolipase by Serratia marcescens. J Bacteriol 138:663-670 